\title{
The Role of Underlayers and Overlayers in Thin Film BiVO 4 Photoanodes for Solar Water Splitting
}

Miguel García-Tecedor, ${ }^{\dagger}$ Drialys Cardenas-Morcoso, ${ }^{\dagger}$ Roser Fernández-Climent, Sixto Giménez,

Dr. Miguel García-Tecedor, Drialys Cárdenas-Morcoso, Roser Fernández-Climent, Dr. Sixto Giménez

Institute of Advanced Materials (INAM), Universitat Jaume I, 12006 Castelló, Spain

E-mail: sjulia@uji.es

Keywords: bismuth vanadate, heteroestructuring, water splitting,

Light-driven water splitting with metal oxide semiconductor materials to produce $\mathrm{H}_{2}$ constitutes one of the most promising energy conversion technologies built on solar power. $\mathrm{BiVO}_{4}$ stands out as one of the most attractive metal oxides with reported photocurrents close to its theoretical maximum of $7.5 \mathrm{~mA} \cdot \mathrm{cm}^{-2}$ at 1 sun illumination. The present mini-review addresses the state-of-the-art strategies to enhance the performance of this material for water oxidation by heterostructuring with different underlayer $\left(\mathrm{SnO}_{2}\right.$ and $\left.\mathrm{WO}_{3}\right)$ and overlayer $(\mathrm{NiOOH} / \mathrm{FeOOH}$, Co-Pi, Co-Fe Prussian Blue derivative) materials, with particular emphasis on the physico-chemical mechanisms responsible for the reported enhancements.

\section{Introduction}

Monoclinic bismuth vanadate $\left(\mathrm{BiVO}_{4}\right)$ stands out as the most promising metal oxide ntype semiconductor material for photoelectrochemical water oxidation. After some initial controversy, it has been demonstrated that the material has an indirect band gap energy of $2.4 \mathrm{eV}(\sim 516 \mathrm{~nm}$ band edge $){ }^{[1]}$ which leads to a maximum theoretical photocurrent of $\sim 7.5 \mathrm{~mA} \cdot \mathrm{cm}^{-2}$ under 1 sun $\mathrm{AM}$ 1.5G illumination and a Solar to Hydrogen (STH) efficiency of $9.2 \%,{ }^{[2]}$ which is close to the technological target for solar driven water-splitting (STH efficiency of 10\%). ${ }^{[3]}$ Its conduction band edge is more positive than the Hydrogen Evolution potential $\left(0 \mathrm{~V}_{\mathrm{RHE}}\right.$, versus Reversible Hydrogen Electrode) and consequently, photogenerated holes lie below $2.4 \mathrm{~V}_{\text {RHE }}$ with a 
large driving force to oxidize water. Compared to other polymorphs of $\mathrm{BiVO}_{4}$, the higher distortion in the local environments of $\mathrm{Bi}$ and $\mathrm{V}$ ions within the monoclinic phase is believed to be at the origin of its superior photocatalytic activity. ${ }^{[4]}$ Electron transport has been recognized as the main limiting factor for performance. ${ }^{[5,6]}$ This poor electron transport is attributed to the crystalline structure of $\mathrm{BiVO}_{4}$ where the $\mathrm{VO}_{4}$ tetrahedral units are not interconnected. ${ }^{[7]} \mathrm{A}$ more recent study claims space chargelimited current in the presence of trap states with no additional recombination sites identified at grain boundaries, suggesting high defect tolerance in this material. ${ }^{[8]}$

On the other hand, charge transfer kinetics at the semiconductor-liquid junction is sluggish and consequently, different strategies have been adopted to enhance the optoelectronic/catalytic properties of $\mathrm{BiVO}_{4}$ aimed at enhancing its photoelectrochemical performance for light-driven water oxidation: (i) nanostructuring in order to ortogonalize light harvesting and carrier diffusion, ${ }^{[9]}$ (ii) extrinsic or intrinsic doping to enhance the electronic conductivity, ${ }^{[10]}$ (iii) heterostructuring with different materials to exploit synergistic interactions between them and (iv) the use of postsynthetic treatments to enhance the performance of photoactive materials in ways that cannot be achieved via direct fabrication methods. ${ }^{[11]}$ The present mini-review focuses on the role that the deposition of underlayers and overlayers play on the photoelectrochemical behavior of $\mathrm{BiVO}_{4}$ based heterostructures, with particular emphasis on the mechanistic description claimed for enhanced performance. For more detailed information on performance metrics, the reader is referred elsewhere.

\section{Underlayers}

\section{1. $\mathrm{SnO}_{2} / \mathrm{BiVO}_{4}$}

Tin oxide, $\mathrm{SnO}_{2}$ has been widely studied as underlayer between Fluorine-doped Tin oxide (FTO) and $\mathrm{BiVO}_{4}{ }^{[12,13]}$ The first report where $\mathrm{SnO}_{2}$ is combined with $\mathrm{BiVO}_{4},{ }^{[14]}$ the role of $\mathrm{SnO}_{2}$ both as an underlayer or as an overlayer was explored. It was concluded that $\mathrm{SnO}_{2}$ as an underlayer improved the electron transfer from $\mathrm{BiVO}_{4}$ to FTO by reducing the recombination pathways at the back contact. However, $\mathrm{SnO}_{2}$ as an overlayer decreased the performance of the photoelectrochemical system due to the formation of a Schottky barrier, preventing the charge transfer of photogenerated holes 
from $\mathrm{BiVO}_{4}$ to the $\mathrm{SnO}_{2} /$ electrolyte interface. More recently, the enhanced performance due to the $\mathrm{SnO}_{2}$ underlayer has been attributed to the passivation of the $\mathrm{FTO} / \mathrm{BiVO}_{4}$ defect states (Figure 1a). ${ }^{[13]}$ It has been claimed that the $\mathrm{FTO} / \mathrm{BiVO}_{4}$ interface presents complex defect states (DFS) able to trap photogenerated electrons before extraction, and consequently leading to decreased performance. These defect states are attributed to oxygen vacancies coupled with $\mathrm{Sn}^{2+}$ species, which can introduce deep levels inside the bandgap of FTO. ${ }^{[13]}$ The presence of oxygen vacancies related defects, usually detected by luminescence, inducing deep states inside the bandgap of $\mathrm{SnO}_{2}$ has been widely reported. ${ }^{[13]}$ Electron trapping by DFS leads to a negative charging of the $\mathrm{FTO} / \mathrm{BiVO}_{4}$ interface, repelling other electrons and flattening the bands. This band flattening effect allows photogenerated holes in $\mathrm{BiVO}_{4}$ to recombine with trapped electrons at DFS, which act as recombination centers at the $\mathrm{FTO} / \mathrm{BiVO}_{4}$ interface. The introduction of the $\mathrm{SnO}_{2}$ underlayer between FTO and $\mathrm{BiVO}_{4}$, block the path of the photogenerated holes to the DFS (hole mirror effect), enhancing charge extraction by reducing the recombination, as depicted in Figure 1a. A more detailed analysis of the role of the $\mathrm{SnO}_{2}$ underlayer involved a thickness dependent study showing that the thicker the $\mathrm{SnO}_{2}$ layer (from $20 \mathrm{~nm}$ up to $65 \mathrm{~nm}$ ), the more effectively passivated the DFS at FTO in the $\mathrm{FTO} / \mathrm{SnO}_{2} / \mathrm{BiVO}_{4}$ heterostructure. ${ }^{[13]}$ This same effect has been already identified for other photoanode material like $\mathrm{Fe}_{2} \mathrm{O}_{3} \cdot{ }^{[15]}$

\section{2. $\mathrm{WO}_{3} / \mathrm{BiVO}_{4}$}

Among the different heterojunctions with $\mathrm{BiVO}_{4}$ underlayers engineered in the last years $\left(\mathrm{WO}_{3}-\mathrm{BiVO}_{4}{ }^{[16]}, \mathrm{SnO}_{2}-\mathrm{BiVO}_{4},{ }^{[13]} \mathrm{Bi}_{2} \mathrm{WO}_{6}-\mathrm{BiVO}_{4}{ }^{[17]}, \mathrm{Co}_{3} \mathrm{O}_{4}-\mathrm{BiVO}_{4}{ }^{[18]}, \mathrm{CuO}-\right.$ $\mathrm{BiVO}_{4}{ }^{[19]}$, etc.), $\mathrm{WO}_{3}-\mathrm{BiVO}_{4}$ has attracted significant attention, due to the highest water oxidation photocurrents obtained $\left(6.72 \mathrm{~mA} \cdot \mathrm{cm}^{-2}\right.$ at $1.23 \mathrm{~V}$ vs RHE), close to the theoretical maximum $\left(7.5 \mathrm{~mA} \cdot \mathrm{cm}^{-2}\right) .{ }^{[2]}$ This heterojunction synergistically combines the excellent conductivity of $\mathrm{WO}_{3}$ with the good absorption properties of $\mathrm{BiVO}_{4}$, in a 


\section{WILEY-VCH}

favorable type II band alignment to promote charge separation leading to a significant reduction of charge recombination. ${ }^{[20]}$ An excellent recent review has extensively described the different synthetic approaches leading to different $\mathrm{WO}_{3} / \mathrm{BiVO}_{4}$ nanostructures. ${ }^{[21]}$ On the other hand, different mechanistic studies have shed light on the carrier dynamics at different timescales in this system. At the ultrafast timescale (fsps), Kamat and Selli studied with Transient Absorption Spectroscopy (TAS) the response of the heterojunction and individual components, showing that under selective $\mathrm{BiVO}_{4}$ excitation, a favorable electron transfer from photoexcited $\mathrm{BiVO}_{4}$ to $\mathrm{WO}_{3}$ occurs immediately after excitation and leading to an enhanced lifetime of the trapped holes at $\mathrm{BiVO}_{4}$. However, upon simultaneous excitation of both oxides, a new recombination channel is activated. This is reflected on a shorter lifetime of the trapped holes in $\mathrm{BiVO}_{4} \cdot{ }^{[22]}$ Furthermore, Hammarström and Selli confirmed through nanosecond mid-IR TA experiments that charge carrier separation occurs in $\mathrm{WO}_{3} / \mathrm{BiVO}_{4}$ electrodes under visible-light excitation, persisting up to the microsecond timescale. Additionally, photogenerated electrons live much longer in $\mathrm{WO}_{3}$ compared to $\mathrm{BiVO}_{4}$, in line with the far better electron conductivity of the former oxide. At more relevant timescale for water oxidation ( $\mu \mathrm{s}-\mathrm{s})$, impedance spectroscopy measurements together with physical modeling were employed to understand the role of $\mathrm{WO}_{3}$ on the enhanced performance of the $\mathrm{WO}_{3} / \mathrm{BiVO}_{4}$ heterostructure. ${ }^{[23]}$ It was hypothesized that the enhancement of the photoelectrochemical performance was due to either a reduction of bulk recombination or to a more favorable electron extraction kinetics at the back contact. The relative contribution of both processes could be easily evaluated by the behavior of the minimum value in the total resistance, evaluated from the $\mathrm{j}-\mathrm{V}$ curve as $R_{d c}=\left(\frac{d \bar{\jmath}}{d V}\right)^{-1}$. A decreased value of the minimum was ascribed to decreased bulk recombination and a cathodic shift was related to more favorable charge extraction at the electron contact. 


\section{WILEY-VCH}

Figure 1c schematically illustrates the dc resistance in two materials with different bulk recombination and electron extraction properties. The material (i) exhibits lower bulk recombination and enhanced electron extraction compared to (ii), as reflected by the lower and cathodically shifted value of the resistance valley. In line with this analysis, $\mathrm{WO}_{3}$ was found to control the transport properties in the heterojunction, significantly reducing bulk recombination by boosting the charge extraction, while $\mathrm{BiVO}_{4}$ was responsible of the enhanced light harvesting properties, which explained the synergistic effect in $\mathrm{WO}_{3}-\mathrm{BiVO}_{4}$ heterostructure.

On the other hand, Kafizas et al ${ }^{[24]}$ have studied the dynamics of photogenerated electron and holes in the $\mathrm{WO}_{3}-\mathrm{BiVO}_{4}$ heterojunction at relevant timescales for water oxidation by using TAS and Transient Photocurrent (TPC) spectroscopy. The origin of the enhanced performance of the $\mathrm{WO}_{3}-\mathrm{BiVO}_{4}$ heterojunction was based on the faster electron transfer from $\mathrm{BiVO}_{4}$ to $\mathrm{WO}_{3}(<\mu \mathrm{s})$ compared to that from $\mathrm{BiVO}_{4}$ to $\mathrm{FTO}(\sim 100$ $\mu \mathrm{s})$. Since the photogenerated electrons in $\mathrm{BiVO}_{4}$ are transferred faster to $\mathrm{WO}_{3}$, bulk recombination at $\mathrm{BiVO}_{4}$ (which dominates at early time scales, $<\mu \mathrm{s}-\mathrm{ms}$, and explains the poor performance of bare $\mathrm{BiVO}_{4}$ ) is significantly reduced, consequently increasing the population of photogenerated holes accumulated at the semiconductor/liquid junction leading to more favorable water oxidation conditions. It is worth noting, that even if electron extraction is slower from $\mathrm{WO}_{3}$ to $\mathrm{FTO}(\sim \mathrm{ms})$ than from $\mathrm{BiVO}_{4}$ to FTO ( 20-100 $\mu \mathrm{s})$, this factor does not limit the enhanced performance of the heterojunction. This was explained on the basis of fast charge transfer from $\mathrm{BiVO}_{4}$ to $\mathrm{WO}_{3}$, concomitantly reducing the bulk recombination losses at $\mathrm{BiVO}_{4}$, as illustrated in Figure $1 b$.

An additional beneficial effect of heterostructuring with $\mathrm{WO}_{3}$ underlayers is the suppresion of the "dead-layer" effect observed in the bare $\mathrm{BiVO}_{4}$ thin layers $(\leq 125$ 


\section{WILEY-VCH}

$\mathrm{nm})$, also reported for other metal oxide photoanodes as hematite. ${ }^{[25]}$ This is probably due to the reduction in lattice mismatch between the back contact (FTO) and the absorber upon deposition of the underlayer.

A more detailed theoretical-experimental study of the $\mathrm{WO}_{3}-\mathrm{BiVO}_{4}$ interface based on Density Functional Theory (DFT) calculations could satisfactorily explain the different photoelectrochemical performance with front and back illumination. ${ }^{[26]}$ The DFT model revealed a non-favorable alignment (non-staggered) between the valence bands of $\mathrm{WO}_{3}$ and $\mathrm{BiVO}_{4}$ attributed to the hybridization of interfacial states (most likely oxygen anions at the $\left.\mathrm{WO}_{3} / \mathrm{BiVO}_{4}\right)$ pinning the valence band. Upon back illumination, the photogenerated holes in $\mathrm{WO}_{3}$ must cross the junction to reach the $\mathrm{BiVO}_{4} /$ electrolyte interface. Since the valence band energies of both materials are pinned, there is not effective driving force to facilitate the travelling of the photogenerated holes, which can more easily recombine with the electrons at $\mathrm{WO}_{3}$, contrary to the favorable band alignment for the extraction of photogenerated electrons at $\mathrm{BiVO}_{4}$ under front illumination. When the heterojunction is front-illuminated, the generation of electronhole pairs is higher compared to the recombination at $\mathrm{BiVO}_{4}$, conversely to the situation in $\mathrm{WO}_{3}$. This has been depicted with the thick and thin arrows in Figure 1b.

In summary, the $\mathrm{WO}_{3}-\mathrm{BiVO}_{4}$ heterojunction improves the performance for water oxidation compared to bare $\mathrm{BiVO}_{4}$, due to a significant reduction of bulk recombination at $\mathrm{BiVO}_{4}$ caused by the fast transfer of the photogenerated electrons to the back contact. This faster electron extraction takes place as a result of the staggered alignement between $\mathrm{WO}_{3}$ and $\mathrm{BiVO}_{4}$, characteristic of a type-II heterojunction. Finally, the double heterojunction $\mathrm{SnO}_{2} / \mathrm{WO}_{3} / \mathrm{BiVO}_{4}$ has also been recently studied, showing enhanced performance with respect to the single heterostrucutured systems described above. ${ }^{[27]}$ This system allows a cascade band alignment facilitating the charge transport across the 
interface. Moreover, the introduction of a $\mathrm{WO}_{3}$ layer between the $\mathrm{SnO}_{2}$ and the $\mathrm{BiVO}_{4}$ also provides slightly enhanced optical absorption under visible light.

\subsection{Other examples}

Other relevant examples of underlayers include $\mathrm{TiO}_{2},{ }^{[28]}$ and $\mathrm{ZnO},{ }^{[29]}$ although most of the published reports are based on heterostructures, where $\mathrm{TiO}_{2}$ or $\mathrm{ZnO}$ act as charge transport/collection layers and $\mathrm{BiVO}_{4}$ as an inorganic sensitizer, overcoming the poor charge transport properties of $\mathrm{BiVO}_{4} \cdot \mathrm{Lu}_{2} \mathrm{O}_{3}$ has also been reported as an efficient hole blocking underlayer, when combined with $\mathrm{BiVO}_{4}$, due to the significant reduction of interfacial defects at the $\mathrm{BiVO}_{4} / \mathrm{Lu}_{2} \mathrm{O}_{3}$ and $\mathrm{Lu}_{2} \mathrm{O}_{3} / \mathrm{ITO}$ interfaces. ${ }^{[30]}$

\section{Overlayers}

The deposition of protective, passivating or catalytic layers on top of $\mathrm{BiVO}_{4}$ has also demonstrated to lead to significant functional improvements for water oxidation. The photoanode/overlayer/electrolyte interface can be more favorable compared to the photoanode/electrolyte, since: (i) The built-in potential generated when the photoanode and the overlayer are brought toguether is independent of the redox potential of the electrolyte. This built-in potentail can be tuned by employing overlayers with appropiated band alignements with $\mathrm{BiVO}_{4}$, improving the photogenerated hole injection through the overlayer into the solution. and (ii), the surface of the overlayer can be designed to minimize the overpotential needed to start extracting photogenerated carriers. ${ }^{[31]}$ On the other hand, the employed overlayers for water splitting applications are often made of noble metal catalysts. ${ }^{[32]}$ However, a real alternative for cost-effective renewable energy sources cannot be based on noble metals. ${ }^{[33]}$ Below, we focus on different overlayer materials based on Earth-abundant elements, like nickel oxide, iron oxide, cobalt phosphate (CoPi) and Prussian Blue derivatives. 


\section{WILEY-VCH}

\section{1. $\mathrm{BiVO}_{4} / \mathrm{NiOOH}$ and $\mathrm{BiVO}_{4} / \mathrm{FeOOH}$}

At present, Earth-abundant Ni-based oxides constitute one of the most attractive water oxidation electrocatalysts to be integrated in photoelectrochemical devices for the production of solar fuels. Kim and Choi improved the electron-hole separation at $\mathrm{BiVO}_{4}$ through nanostructuring and minimized the recombination losses at the $\mathrm{BiVO}_{4} /$ electrolyte interface by the deposition of two different catalytic overlayers (FeOOH and $\mathrm{NiOOH})$, boosting the hole injection efficiency into the solution. ${ }^{[34]}$ More specifically, a record charge separation efficiency was obtained by reducing the particle size of the nanoporous $\mathrm{BiVO}_{4}(30-75 \mathrm{~nm})$ below the hole diffusion length $(\sim 100 \mathrm{~nm})$. However, it was observed that the majority of the photogenerated holes recombined before being injected into the solution. Consequently, two different catalytic overlayers $(\mathrm{NiOOH}$ and $\mathrm{FeOOH})$ were deposited on top of the nanoporous $\mathrm{BiVO}_{4}$. Although the obtained photocurrents were significantly higher in the presence of the catalytic overlayers, they were lower compared to that of bare $\mathrm{BiVO}_{4}$ in the hole scavenger. This suggested that the recombination pathways were not totally suppressed by these overlayers. $\mathrm{BiVO}_{4} / \mathrm{NiOOH}$ showed higher surface recombination and a more cathodic onset and higher photocurrents compared to $\mathrm{BiVO}_{4} / \mathrm{FeOOH}$, due to a more favorable potential drop at the Helmholtz layer. As a next step, the complex systems $\mathrm{BiVO}_{4} / \mathrm{NiOOH} / \mathrm{FeOOH}$ and $\mathrm{BiVO}_{4} / \mathrm{FeOOH} / \mathrm{NiOOH}$ were also investigated, and a photocurrent density of $2.73 \mathrm{~mA} \mathrm{~cm}^{-2}$ at $0.6 \mathrm{~V}_{\mathrm{RHE}}$ was obtained for the latter case. This was attributed to the combination of two beneficial factors: (i) the FeOOH layer reduced the recombination at the $\mathrm{BiVO}_{4} / \mathrm{FeOOH}$ interface, while (ii) the $\mathrm{NiOOH}$ catalyst reduced the potential drop at the Helmholtz layer at the $\mathrm{NiOOH} /$ solution interface shifting cathodically the $\mathrm{BiVO}_{4}$ flat band potential (which also shifted the photocurrent onset to more negative potentials). More specifically, FeOOH/NiOOH has been 
reported as one of the best oxygen evolution catalysts for $\mathrm{BiVO}_{4}$ due to its excellent surface kinetics for water oxidation. ${ }^{[35]}$

Remarkable improvement of the long-term stability was achieved by saturating the electrolyte with $\mathrm{V}^{5+}$ ions in order to prevent the photocorrosion. ${ }^{[36]} \mathrm{BiVO}_{4}$ is usually unstable under anodic bias and long-term illumination. The degradation process mainly involves the dissolution of $\mathrm{V}^{5+}$ species, caused by photo-oxidation, which segregates from the $\mathrm{BiVO}_{4}$ lattice leading to a concomitant decrease in performance. Some of the photogenerated holes which accumulate at the $\mathrm{BiVO}_{4} /$ electrolyte interface take part in this photocorrosion process. By saturating the employed borate buffer with $\mathrm{V}^{5+}$ ions, the photocorrosion was totally suppressed for $60 \mathrm{~h}$, without any change in the water oxidation kinetics. In addition, the presence of $\mathrm{V}^{5+}$ ions in the electrolyte can form an interfacial $\mathrm{Fe} / \mathrm{Ni}-\mathrm{V}-\mathrm{O}$ layer between the $\mathrm{BiVO}_{4}$ and the $\mathrm{NiOOH} / \mathrm{FeOOH}$ catalysts, inducing high stability $(\sim 450 \mathrm{~h})$ under illumination and anodic bias, enhancing water oxidation kinetics.

\section{2 $\mathrm{BiVO}_{4} / \mathrm{Co}-\mathrm{Pi}$}

Cobalt phosphate $(\mathrm{Co}-\mathrm{Pi}),{ }^{[37]}$ is a well-known, efficient and earth-abundant electrocatalyst and consequently, its coupling with photo-absorbers for photoelectrochemical water splitting, including $\mathrm{BiVO}_{4}$, has been widely studied. Several authors have reported increased charge injection efficiency and consequently, enhanced water oxidation kinetics when using Co-Pi modified BiVO 4 photoanodes. ${ }^{[5,38,39]}$ However, the origin of such improvements is currently under debate, since two different mechanisms can explain the observed enhanced photoelectrochemical behavior: (i) suppression of surface recombination at the $\mathrm{BiVO}_{4} /$ solution interface (Figure 2a) and (ii) "true" catalytic activity via Co-Pi enhancing charge transfer kinetics (Figure 2b). Mechanism (i) was claimed first by Gamelin and co-workers, who observed a large (ca $440 \mathrm{mV}$ ) 


\section{WILEY-VCH}

cathodic shift of the onset potential for OER after photo-assisted electrodeposition of Co-Pi onto $\mathrm{W}: \mathrm{BiVO}_{4}$ photoanodes. ${ }^{[38]}$ Experiments with and without a sacrificial hole scavenger ( $\mathrm{j}-\mathrm{V}$ curves and chronoamperometric tests) concluded that the modification of $\mathrm{BiVO}_{4}$ photoanodes with $\mathrm{Co}-\mathrm{Pi}$, yielded to nearly complete suppression of recombination losses, together with enhanced charge injection efficiency.

A more detailed mechanistic study was carried out by Durrant and coworkers using Photo Induced Absorption Spectroscopy (PIAS) and Spectroelectrochemistry (SEC). ${ }^{[40]}$ A significantly larger PIAS signal was observed on Co-Pi modified $\mathrm{BiVO}_{4}$, attributed to an additional photoinduced species, rather than to photogenerated holes in $\mathrm{BiVO}_{4}$. By comparing with SEC data for Co-Pi/FTO, the large PIAS signal observed for Co-Pi modified $\mathrm{BiVO}_{4}$ was assigned to the oxidation of $\mathrm{Co}^{2+}$ to $\mathrm{Co}^{3+}$. Furthermore, the analysis of steady-state photocurrent during SEC showed that electrochemical water oxidation by Co-Pi takes place with a density of $\mathrm{Co}^{3+}$ sites of $1 \times 10^{17} \mathrm{~cm}^{-2}$, three times higher compared to that for the Co-Pi modified $\mathrm{BiVO}_{4}$ under water oxidation condition. Since the hole transfer kinetics from $\mathrm{BiVO}_{4}$ was still faster compared to that via Co-Pi oxidation states, it was concluded that Co-Pi did not significantly contribute to the overall water oxidation photocurrent, which was instead enhanced by the capability of Co-Pi to retard electron/hole recombination at the $\mathrm{BiVO}_{4} /$ solution interface. Similar conclusions were obtained by Abdi and co-workers, through Incident Modulated Photocurrent Spectroscopy (IMPS) measurements. ${ }^{[41]}$ In these experiments, light intensity is used to modulate the surface concentration of the photo-generated carriers, and consequently both the potential across the space charge region and the reaction rate constants remain unaltered. Therefore, the hole injection into the electrolyte and surface recombination at the semiconductor/electrolyte interface can be clearly differentiated. At low applied potentials, surface recombination rate constant $\left(\mathrm{k}_{\mathrm{rec}}\right)$ was reduced by the 
introduction of electrodeposited $\mathrm{Co}-\mathrm{Pi}$, and this was attributed to the passivation of surface recombination sites. Then, $\mathrm{k}_{\mathrm{rec}}$ decreased with increasing potential, which was attributed to the formation of oxidized species, with higher intrinsic catalytic activity compared to $\mathrm{BiVO}_{4}$, due to the oxidation of Co-Pi by the increasing fraction of photogenerated holes. On the other hand, the charge transfer rate constant $\left(\mathrm{k}_{\mathrm{tr}}\right)$ was not affected in the presence of Co-Pi, suggesting that charge transfer still occurs via the $\mathrm{BiVO}_{4}$ surface. This conclusion was also supported by in situ UV-Vis absorption measurements, also suggesting the gradual shift of water oxidation from the $\mathrm{BiVO}_{4}$ surface to the Co-Pi, at higher applied potentials. Despite all these mechanistic studies, the chemical nature of the surface defects and the accurate passivation mechanism via Co-Pi modification are still elusive. Nonetheless, these studies clearly concluded that electrocatalysis is not the main function of Co-Pi in these systems.

A different mechanistic picture of the role of $\mathrm{CoPi}$ on $\mathrm{BiVO}_{4}$ was provided by Boettcher and collaborators. ${ }^{[42,43]}$ They could directly measure the charging of the Co-Pi overlayer by the photogenerated holes in $\mathrm{BiVO}_{4}$ by using an electrochemical Atomic Force Microscopy (AFM) as a second working electrode. A rise in the Co-Pi potential detected at the onset of the photocurrent revealed how the photogenerated holes in the absorber layer were collected by the CoPi catalyst. By comparing both FTO/Co-Pi and $\mathrm{BiVO}_{4} / \mathrm{Co}-\mathrm{Pi}$, it was possible to demonstrate the accumulation of photogenerated holes at $\mathrm{BiVO}_{4}$ within the $\mathrm{Co}-\mathrm{Pi}$ overlayer until enough anodic potential was reached for water oxidation. Consequently, Co-Pi was found to act as a hole reservoir of photogenerated charges at $\mathrm{BiVO}_{4}$, behaving as a "true" oxygen evolution catalyst. It was concluded that the holes involved in the oxidation of water were firstly transferred to the Co-Pi catalyst, and OER did not take place on the $\mathrm{BiVO}_{4}$ surface. A systematic 
analysis of identical photoelectrodes with different spectroscopic and electrochemical tools would help to reconcile both interpretations.

\section{3. $\mathrm{BiVO}_{4} / \mathrm{Co}-\mathrm{Fe}$ Prussian Blue derivatives}

As an attractive alternative to metal oxides-based water oxidation catalysts like $\mathrm{NiOOH}$ and $\mathrm{FeOOH}$ or to $\mathrm{Co}-\mathrm{Pi}$, which cracks upon drying of the electrode, the Prussian Blue derivatives (metal hexacyanometallate structures) have demonstrated exceptional activity and stability in neutral an acid media ${ }^{[44]}$ and the possibility to be easily prepared and processed by soft chemistry methods, both as nanoparticles and thin film, from Earth abundant materials. Their unique electronic and structural features ${ }^{[45,}$ 46, 47], as well as their versatile redox properties, ${ }^{[48]}$ have made possible their use as catalyst for oxidation of $\mathrm{H}_{2} \mathrm{O}_{2}{ }^{[49]}$ and organic compounds. ${ }^{[50]}$ The electrocatalytic activity for water oxidation of Prussian Blue analogues was firstly investigated by Galán-Mascaros and co-workers in 2013 with the cobalt iron analogue ${ }^{[45]}$ (cobalt hexacyanoferrate; from now CoFe-PB). Since then, several authors have also reported effective water oxidation catalysis with Prussian Blue coordinated polymers. ${ }^{[44,46,51]}$

A recent report described a heterostructured $\mathrm{BiVO}_{4} / \mathrm{CoFe}-\mathrm{PB}$ photoanode with a 10-fold enhancement of the photocurrent with respect to bare $\mathrm{BiVO}_{4}$, a shift of the onset potential of $0.8 \mathrm{~V}$ vs RHE (Figure 3a) and excellent stability through c.a. $55 \mathrm{~h}$

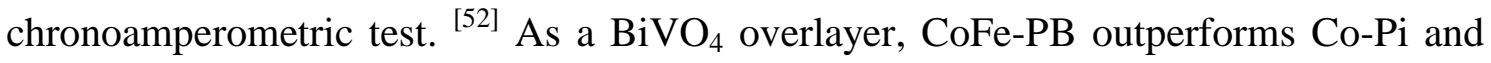
FeOOH. Mechanistic studies with impedance spectroscopy and linear voltammetry in the presence of a sacrificial hole scavenger, showed that the origin of the functional improvement was related to the more efficient hole transfer to the solution via $\mathrm{CoFe}-\mathrm{PB}$ layer, indicating that CoFe-PB could effectively act as a "true" catalyst. This was also supported by hybrid density functional theory (DFT) calculations, which predicted the existence of a strong energetic offset (thermodynamic driving force) for hole transfer 


\section{WILEY-VCH}

from the valence band of $\mathrm{BiVO}_{4}$ to the Co states of $\mathrm{CoFe}-\mathrm{PB}$ and then to water (Figure 3b)

In good agreement with these findings, a more detailed mechanistic investigation with TAS demonstrated that the holes from $\mathrm{BiVO}_{4}$ were quickly and efficiently transferred to $\mathrm{CoFe}-\mathrm{PB}$, leading to persistent oxidized CoFe-PB states. ${ }^{[53]}$ TAS showed the appearance of a long-lived oxidized $\mathrm{CoFe}-\mathrm{PB}^{+}$on a sub-microsecond $(\mu \mathrm{s})$ time-scale, even under very low applied bias. This indicated that photogenerated holes in $\mathrm{BiVO}_{4}$ rapidly transferred to $\mathrm{CoFe}-\mathrm{PB}$. This observation was also supported by PIAS, which emulates in operando water oxidation conditions. In this case, the appearance of $\mathrm{CoFe}-\mathrm{PB}^{+}$was also observed, and also a doubly oxidized $\mathrm{CoFe}-\mathrm{PB}^{2+}$ species, upon further oxidation of $\mathrm{CoFe}-\mathrm{PB}^{+}$. On the other hand, the typical $\mathrm{BiVO}_{4}$ hole signal vanished, and consequently the $\mathrm{CoFe}-\mathrm{PB}^{2+}$ state was assumed to be the catalytically active species for water oxidation. Consequently, the $\mathrm{BiVO}_{4} / \mathrm{CoFe}-\mathrm{PB}$ heterostructure led to fast $(\mu \mathrm{s})$ interfacial hole transfer, with concomitant suppression of electron-hole recombination at $\mathrm{BiVO}_{4}$ and, consequently to enhanced water oxidation performance (Figure 3c).

\subsection{Other examples}

Some other relevant overlayers on $\mathrm{BiVO}_{4}$ include $\mathrm{TiO}_{2}$ (or defective $\mathrm{TiO}_{\mathrm{x}}$ ). On discontinous $\mathrm{BiVO}_{4}$ layers, coating the $\mathrm{FTO} / \mathrm{BiVO}_{4}$ structures with amorphous $\mathrm{TiO}_{2}$ leads to the effective blocking of surface recombination and to solution-mediated recombination at surface defects and at exposed regions of the conductive substrate. ${ }^{[54]}$ Similar mechanistic enhancement has been suggested for the heterostructured $\mathrm{WO}_{3} / \mathrm{BiVO}_{4}$ system. ${ }^{[55]}$ Furthermore, $\mathrm{TiO}_{2}{ }^{[56]}$ and $\mathrm{TiO}_{2} / \mathrm{Ni}^{[57]}$ dual layers have been reported to enable water oxidation with $\mathrm{BiVO}_{4}$ in basic media providing effective protection against photocorrosion. Another interesting example involves mixed $\mathrm{CeO}_{2}$ 
overlayers $\left(\mathrm{Fe}_{0.26} \mathrm{Ce}_{0.74} \mathrm{O}_{z}\right)$. These overlayers have demonstrated the removal of surface states, enabling efficient hole extraction from $\mathrm{BiVO}_{4}$ while deactivating recombination. ${ }^{[58]}$ On the other hand, amorphous $\mathrm{Co}-$ La mixed double hydroxides $(\mathrm{MDH})$ on $\mathrm{BiVO}_{4} / \mathrm{FTO}$ have showed to reduce charge recombination and enhance transport by controlling the grain size. ${ }^{[59]} \mathrm{In}_{2} \mathrm{O}_{3}$ has also been used as overlayer on $\mathrm{BiVO}_{4}$, enhancing both separation and injection efficiencies. ${ }^{[60]}$ Finally, ultra-thin $\mathrm{Al}_{2} \mathrm{O}_{3}$ coatings also showed enhanced water oxidation kinetics, which was not due to improved reaction kinetics, but rather, inhibited bi-molecular recombination and increased the yield of long-lived holes for water oxidation. ${ }^{[61]}$

\section{Conclusions}

We have showed that interfacing metal oxide semiconductors like $\mathrm{BiVO}_{4}$ with different underlayers and overlayers provides a convenient materials design platform to exploit synergistic interaction between different constituents. The functional enhancements for solar-driven water oxidation observed upon heterostructuring $\mathrm{BiVO}_{4}$ can be ascribed to different processes like suppression of bulk and surface recombination, passivation of defect states, or boosting the catalytic activity. Consequently, the detailed understanding of operating mechanisms is essential to unravel the limitations of these heterostructured devices. Therefore, an accurate mechanistic description is key to wisely select the best combination of underlayer/overlayers for each material under study. Furthermore, synthetic modifications and post-synthetic treatments combined to the deposition of underlayers and overlayers constitute a novel paradigm to target theoretical efficiencies on metal oxide photoelectrodes. 


\section{WILEY-VCH}

\section{Acknowledgements}

We would like to acknowledge financial support from the Ministerio de Ciencia, Innovación y Universidades of Spain (ENE2017-85087-C3-1-R). ${ }^{\dagger}$ Both authors have equally contributed to the present manuscript.

Received: ((will be filled in by the editorial staff))

Revised: ((will be filled in by the editorial staff)) Published online: ((will be filled in by the editorial staff))

\section{References}

[1] J. K. Cooper, S. Gul, F. M. Toma, L. Chen, P.-A. Glans, J. Guo, J. W. Ager, J. Yano, I. D. Sharp, Chemistry of Materials 2014, 26, 5365; J. K. Cooper, S. Gul, F. M.

Toma, L. Chen, Y.-S. Liu, J. Guo, J. W. Ager, J. Yano, I. D. Sharp, The Journal of Physical Chemistry C 2015, 119, 2969.

[2] Y. Pihosh, I. Turkevych, K. Mawatari, J. Uemura, Y. Kazoe, S. Kosar, K. Makita, T. Sugaya, T. Matsui, D. Fujita, M. Tosa, M. Kondo, T. Kitamori, Scientific Reports 2015, 5, 11141.

[3] B. A. Pinaud, J. D. Benck, L. C. Seitz, A. J. Forman, Z. Chen, T. G. Deutsch, B. D. James, K. N. Baum, G. N. Baum, S. Ardo, H. Wang, E. Miller, T. F. Jaramillo, Energy \& Environmental Science 2013, 6, 1983.

[4] S. Tokunaga, H. Kato, A. Kudo, Chemistry of Materials 2001, 13, 4624.

[5] F. F. Abdi, R. van de Krol, The Journal of Physical Chemistry C 2012, 116, 9398.

[6] K. Zhang, X.-J. Shi, J. K. Kim, J. H. Park, Physical Chemistry Chemical Physics 2012, 14, 11119.

[7] A. Walsh, Y. Yan, M. N. Huda, M. M. Al-Jassim, S.-H. Wei, Chemistry of Materials 2009, 21, 547; F. F. Abdi, T. J. Savenije, M. M. May, B. Dam, R. van de Krol, The Journal of Physical Chemistry Letters 2013, 4, 2752; J. Ravensbergen, F. F. 


\section{WILEY-VCH}

Abdi, J. H. van Santen, R. N. Frese, B. Dam, R. van de Krol, J. T. M. Kennis, The Journal of Physical Chemistry C 2014, 118, 27793.

[8] J. Eichhorn, C. Kastl, J. K. Cooper, D. Ziegler, A. M. Schwartzberg, I. D. Sharp, F. M. Toma, Nature Communications 2018, 9, 2597.

[9] Z.-F. Huang, L. Pan, J.-J. Zou, X. Zhang, L. Wang, Nanoscale 2014, 6, 14044.

[10] S. P. Berglund, A. J. E. Rettie, S. Hoang, C. B. Mullins, Physical Chemistry Chemical Physics 2012, 14, 7065; H. Ye, J. Lee, J. S. Jang, A. J. Bard, The Journal of Physical Chemistry C 2010, 114, 13322.

[11] B. Lamm, B. J. Trześniewski, H. Döscher, W. A. Smith, M. Stefik, ACS Energy Letters 2018, 3, 112.

[12] S. Byun, B. Kim, S. Jeon, B. Shin, Journal of Materials Chemistry A 2017, 5, 6905; P. Chatchai, Y. Murakami, S. y. Kishioka, A. Y. Nosaka, Y. Nosaka, Electrochemical and Solid State Letters 2008, 11, H160.

[13] Y. Liang, T. Tsubota, L. P. A. Mooij, R. van de Krol, The Journal of Physical Chemistry C 2011, 115, 17594.

[14] P. Chatchai, Y. Murakami, S.-y. Kishioka, A. Nosaka, Y. Nosaka, Electrochemical and Solid-State Letters 2008, 11, H160.

[15] Y. Liang, C. S. Enache, R. van de Krol, International Journal of Photoenergy 2008, 2008.

[16] J. Su, L. Guo, N. Bao, C. A. Grimes, Nano letters 2011, 11, 1928; B. S. Kalanoor, H. Seo, S. S. Kalanur, Materials Science for Energy Technologies 2018; P. Chatchai, Y. Murakami, S.-y. Kishioka, A. Y. Nosaka, Y. Nosaka, Electrochimica Acta 2009, 54, 1147; P. M. Rao, L. Cai, C. Liu, I. S. Cho, C. H. Lee, J. M. Weisse, P. Yang, X. Zheng, Nano letters 2014, 14, 1099; Y. Pihosh, I. Turkevych, K. Mawatari, T. Asai, 


\section{WILEY-VCH}

T. Hisatomi, J. Uemura, M. Tosa, K. Shimamura, J. Kubota, K. Domen, Small 2014, 10, 3692.

[17] P. Ju, P. Wang, B. Li, H. Fan, S. Ai, D. Zhang, Y. Wang, Chemical Engineering Journal 2014, 236, 430.

[18] M. Long, W. Cai, J. Cai, B. Zhou, X. Chai, Y. Wu, The Journal of Physical Chemistry B 2006, 110, 20211; X. Chang, T. Wang, P. Zhang, J. Zhang, A. Li, J. Gong, Journal of the American Chemical Society 2015, 137, 8356.

[19] H.-q. Jiang, H. Endo, H. Natori, M. Nagai, K. Kobayashi, Materials Research Bulletin 2009, 44, 700; W. Zhao, Y. Wang, Y. Yang, J. Tang, Y. Yang, Applied Catalysis B: Environmental 2012, 115, 90.

[20] S. J. Hong, S. Lee, J. S. Jang, J. S. Lee, Energy \& Environmental Science 2011, 4, 1781.

[21] B. S. Kalanoor, H. Seo, S. S. Kalanur, Materials Science for Energy Technologies 2018, 1, 49.

[22] I. Grigioni, K. G. Stamplecoskie, E. Selli, P. V. Kamat, The Journal of Physical Chemistry C 2015, 119, 20792; I. Grigioni, K. G. Stamplecoskie, D. H. Jara, M. V. Dozzi, A. Oriana, G. Cerullo, P. V. Kamat, E. Selli, ACS Energy Letters 2017, 2, 1362.

[23] X. Shi, I. Herraiz-Cardona, L. Bertoluzzi, P. Lopez-Varo, J. Bisquert, J. H. Park, S. Gimenez, Physical Chemistry Chemical Physics 2016, 18, 9255.

[24] S. Selim, L. Francàs, M. García-Tecedor, S. Corby, C. Blackman, S. Gimenez, J. R. Durrant, A. Kafizas, Chemical Science 2019.

[25] L. Steier, I. Herraiz - Cardona, S. Gimenez, F. Fabregat - Santiago, J. Bisquert, S. D. Tilley, M. Grätzel, Advanced Functional Materials 2014, 24, 7681; O. Zandi, B. M. Klahr, T. W. Hamann, Energy \& Environmental Science 2013, 6, 634. 


\section{WILEY-VCH}

[26] C. R. i Bellés, S. Selim, N. M. Harrison, E. A. Ahmad, A. Kafizas, Sustainable Energy \& Fuels 2019, 3, 264.

[27] J. H. Baek, B. J. Kim, G. S. Han, S. W. Hwang, D. R. Kim, I. S. Cho, H. S. Jung, ACS Applied Materials \& Interfaces 2017, 9, 1479; S. S. M. Bhat, S. A. Lee, J. M. Suh, S.-P. Hong, H. W. Jang, Applied Sciences-Basel 2018, 8.

[28] Y. Jia, Z. Wang, Y. Ma, J. Liu, W. Shi, Y. Lin, X. Hu, K. Zhang, Electrochimica Acta 2019, 300, 138; R. Tong, X. Wang, X. Zhou, Q. Liu, H. Wang, X. Peng, X. Liu, Z. Zhang, H. Wang, P. D. Lund, International Journal of Hydrogen Energy 2017, 42, 5496; X. Zhang, B. Zhang, K. Cao, J. Brillet, J. Chen, M. Wang, Y. Shen, Journal of Materials Chemistry A 2015, 3, 21630.

[29] L. Zhang, E. Reisner, J. J. Baumberg, Energy \& Environmental Science 2014, 7, 1402; L. Yan, W. Zhao, Z. Liu, Dalton Transactions 2016, 45, 11346; S. J. A. Moniz, J. Zhu, J. Tang, Advanced Energy Materials 2014, 4, 1301590; J.-S. Yang, J.-J. Wu, Nano Energy 2017, 32, 232; K. Kim, J. H. Moon, ACS Applied Materials \& Interfaces 2018, 10,34238 .

[30] W. Zhang, D. Yan, X. Tong, M. Liu, Advanced Functional Materials 2018, 28, 1705512.

[31] F. Lin, B. F. Bachman, S. W. Boettcher, The journal of physical chemistry letters 2015, 6, 2427; M. R. Nellist, F. A. L. Laskowski, F. Lin, T. J. Mills, S. W. Boettcher, Accounts of Chemical Research 2016, 49, 733.

[32] S. D. Tilley, M. Cornuz, K. Sivula, M. Grätzel, Angewandte Chemie International Edition 2010, 49, 6405; R. Lalrempuia, N. D. McDaniel, H. Müller Bunz, S. Bernhard, M. Albrecht, Angewandte Chemie International Edition 2010, 49, 9765; L. Duan, F. Bozoglian, S. Mandal, B. Stewart, T. Privalov, A. Llobet, L. Sun, 


\section{WILEY-VCH}

Nature chemistry 2012, 4, 418; Z. Liu, W. Hou, P. Pavaskar, M. Aykol, S. B. Cronin, Nano letters 2011, 11, 1111.

[33] I. Roger, M. A. Shipman, M. D. Symes, Nature Reviews Chemistry 2017, 1, 0003.

[34] T. W. Kim, K.-S. Choi, Science 2014, 1245026.

[35] J. H. Kim, J.-W. Jang, Y. H. Jo, F. F. Abdi, Y. H. Lee, R. van de Krol, J. S. Lee, Nature Communications 2016, 7, 13380; S. Wang, P. Chen, Y. Bai, J.-H. Yun, G. Liu, L. Wang, Advanced Materials 2018, 30, 1800486.

[36] D. K. Lee, K.-S. Choi, Nature Energy 2018, 3, 53.

[37] M. W. Kanan, D. G. Nocera, Science 2008, 321, 1072.

[38] D. K. Zhong, S. Choi, D. R. Gamelin, Journal of the American Chemical Society 2011, 133, 18370.

[39] F. F. Abdi, N. Firet, R. van de Krol, ChemCatChem 2013, 5, 490.

[40] Y. Ma, A. Kafizas, S. R. Pendlebury, F. Le Formal, J. R. Durrant, Advanced Functional Materials 2016, 26, 4951.

[41] C. Zachäus, F. F. Abdi, L. M. Peter, R. van de Krol, Chemical Science 2017, 8, 3712.

[42] M. R. Nellist, J. Qiu, F. A. L. Laskowski, F. M. Toma, S. W. Boettcher, ACS Energy Letters 2018, 3, 2286.

[43] F. A. L. Laskowski, M. R. Nellist, J. Qiu, S. W. Boettcher, Journal of the American Chemical Society 2019, 141, 1394.

[44] L. Han, P. Tang, Á. Reyes-Carmona, B. Rodríguez-García, M. Torréns, J. R. Morante, J. Arbiol, J. R. Galan-Mascaros, Journal of the American Chemical Society 2016, 138, 16037. 


\section{WILEY-VCH}

[45] S. Pintado, S. Goberna-Ferrón, E. C. Escudero-Adán, J. R. Galán-Mascarós, Journal of the American Chemical Society 2013, 135, 13270.

[46] S. Goberna-Ferrón, W. Y. Hernández, B. Rodríguez-García, J. R. GalánMascarós, ACS Catalysis 2014, 4, 1637; A. Indra, U. Paik, T. Song, Angewandte Chemie International Edition 2018, 57, 1241; E. P. Alsaç, E. Ülker, S. V. K. Nune, Y. Dede, F. Karadas, Chemistry - A European Journal 2018, 24, 4856.

[47] M. Aksoy, S. V. K. Nune, F. Karadas, Inorganic Chemistry 2016, 55, 4301.

[48] N. R. de Tacconi, K. Rajeshwar, R. O. Lezna, Chemistry of Materials 2003, 15, 3046; A. A. Karyakin, Electroanalysis 2001, 13, 813.

[49] Y. Zhang, G. S. Wilson, Journal of Electroanalytical Chemistry 1993, 345, 253.

[50] S. R. Ali, V. K. Bansal, A. A. Khan, S. K. Jain, M. A. Ansari, Journal of Molecular Catalysis A: Chemical 2009, 303, 60; S. A. Jaffari, A. P. F. Turner, Biosensors and Bioelectronics 1997, 12, 1.

[51] X. Zhang, J. He, Journal of Nanoscience and Nanotechnology 2018, 18, 5674;

B. Rodríguez-García, Á. Reyes-Carmona, I. Jiménez-Morales, M. Blasco-Ahicart, S. Cavaliere, M. Dupont, D. Jones, J. Rozière, J. R. Galán-Mascarós, F. Jaouen, Sustainable Energy \& Fuels 2018, 2, 589.

[52] F. S. Hegner, I. Herraiz-Cardona, D. Cardenas-Morcoso, N. López, J.-R. GalánMascarós, S. Gimenez, ACS Applied Materials \& Interfaces 2017, 9, 37671.

[53] B. Moss, F. S. Hegner, S. Corby, S. Selim, L. Francàs, N. López, S. Giménez, J.R. Galán-Mascarós, J. R. Durrant, ACS Energy Letters 2019, 4, 337.

[54] D. Eisenberg, H. S. Ahn, A. J. Bard, Journal of the American Chemical Society 2014, 136, 14011.

[55] S. S. Kalanur, I.-H. Yoo, J. Park, H. Seo, Journal of Materials Chemistry A 2017, 5, 1455. 


\section{WILEY-VCH}

[56] D. Lee, A. Kvit, K.-S. Choi, Chemistry of Materials 2018, 30, 4704.

[57] M. T. McDowell, M. F. Lichterman, J. M. Spurgeon, S. Hu, I. D. Sharp, B. S. Brunschwig, N. S. Lewis, The Journal of Physical Chemistry C 2014, 118, 19618.

[58] A. Shinde, G. Li, L. Zhou, D. Guevarra, S. K. Suram, F. M. Toma, Q. Yan, J. A. Haber, J. B. Neaton, J. M. Gregoire, Journal of Materials Chemistry A 2016, 4, 14356.

[59] M. Chhetri, S. Dey, C. N. R. Rao, ACS Energy Letters 2017, 2, 1062.

[60] W. Qiu, Y. Huang, S. Tang, H. Ji, Y. Tong, The Journal of Physical Chemistry C 2017, 121, 17150.

[61] A. Kafizas, X. Xing, S. Selim, C. A. Mesa, Y. Ma, C. Burgess, M. A. McLachlan, J. R. Durrant, Catalysis Today 2019, 321-322, 59. 


\section{WILEY-VCH}

TOC text

The deposition of underlayers and overlayers on photoactive semiconductor materials for water oxidation, like $\mathrm{BiVO}_{4}$ constitutes a successful strategy to attain high conversion efficiencies. In this context, the present minireview provides a timely description of the most relevant approaches carried out in the last years with particular emphasis on the mechanisms leading to enhanced functional performance.

Keyword: photoelectrochemical water splitting

Miguel García-Tecedor, Drialys Cárdenas-Morcoso, Roser Fernández-Climent, Sixto Giménez

The Role of Underlayers and Overlayers in Thin Film $\mathrm{BiVO}_{4}$ Photoanodes for Solar Water Splitting

ToC figure ((Please choose one size: $55 \mathrm{~mm}$ broad $\times 50 \mathrm{~mm}$ high or $110 \mathrm{~mm}$ broad $\times$ $20 \mathrm{~mm}$ high. Please do not use any other dimensions))

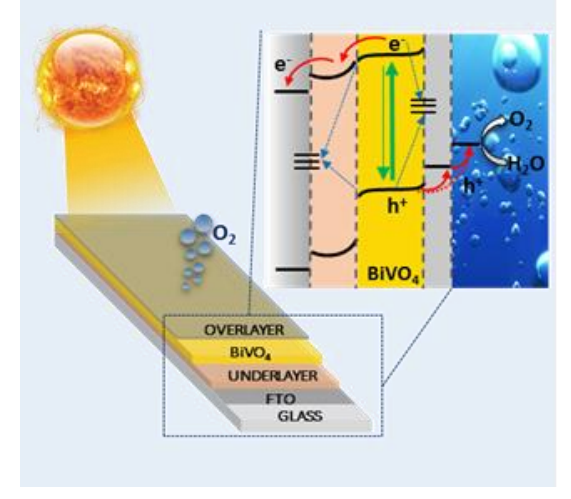


WILEY-VCH
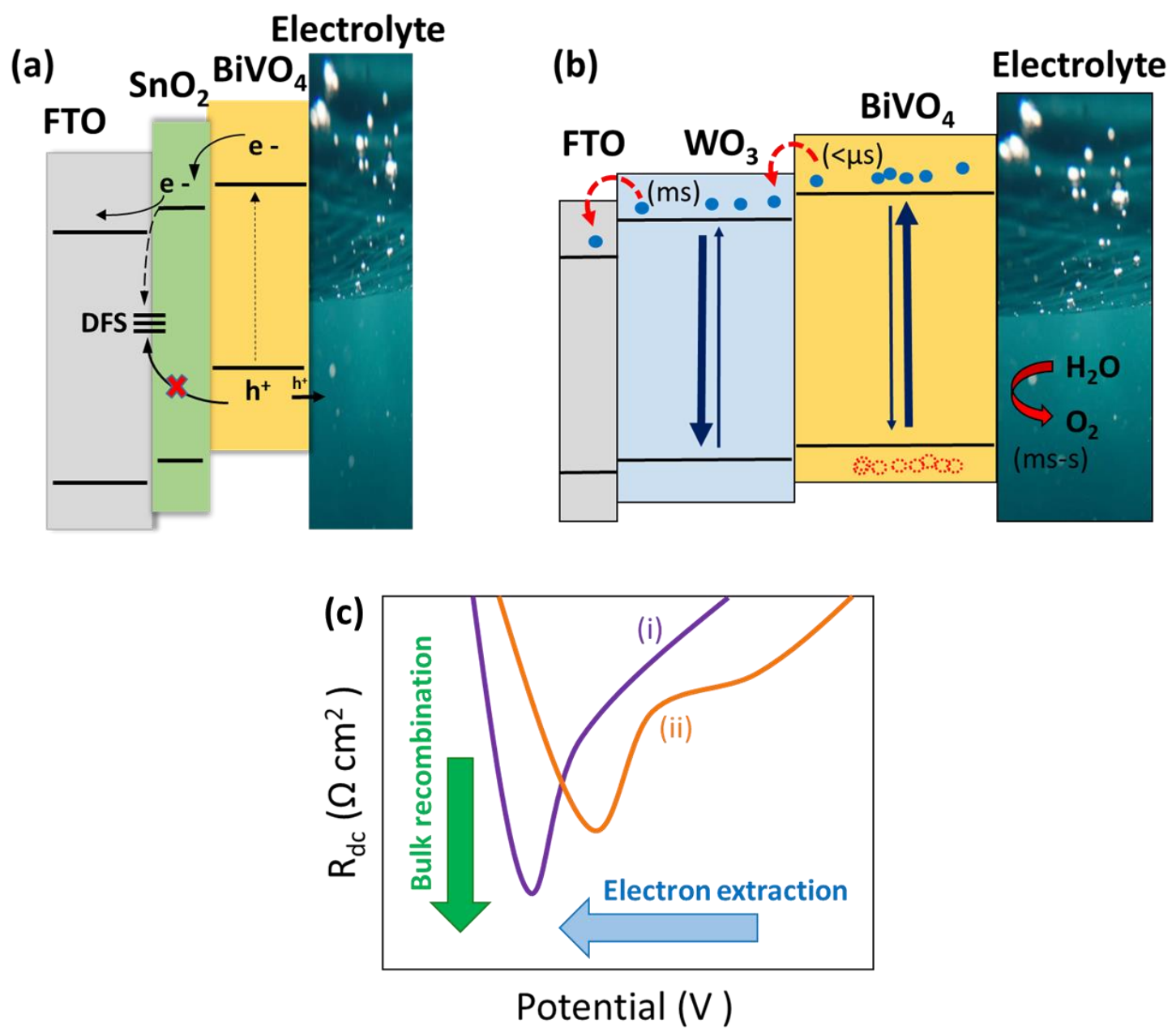

Figure 1.- Schemes inspired in references [13] and [23], showing the band alignment in (a) $\mathrm{FTO} / \mathrm{SnO}_{2} / \mathrm{BiVO}_{4}$ (Adapted with permission from J. Phys. Chem. C, 2011, 115 (35), 17594-17598. Copyright 2011 American Chemical Society) and (b) FTO/ $\mathrm{WO}_{3} / \mathrm{BiVO}_{4}$ heterostructures. (c) dc resistance illustrating two materials with different bulk recombination and surface recombination velocity at the selective contact for electrons. Adapted from reference [23] with permission of the PCCP Owner Societies. 
(a)

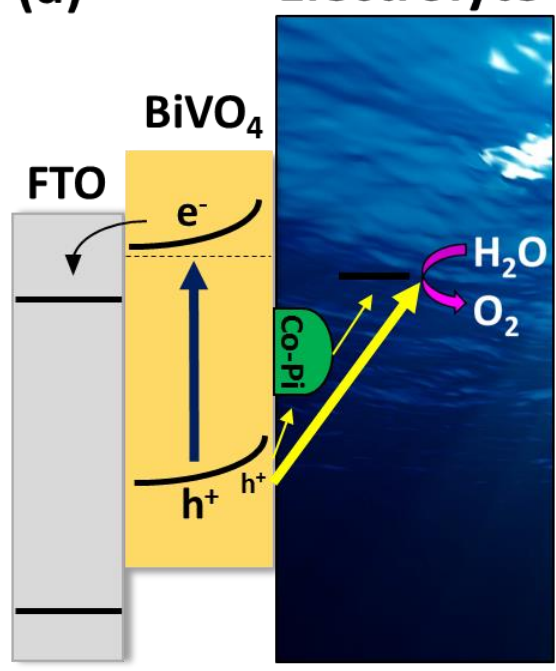

(b)

Electrolyte

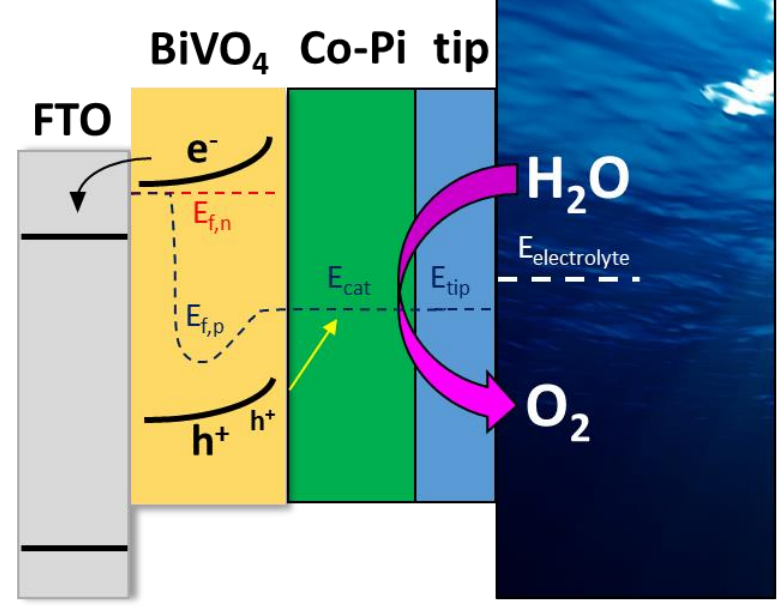

Figure 2. Proposed band diagrams for acting mechanisms in Co-Pi modified $\mathrm{BiVO}_{4}$ photoanodes: (a) Co-Pi acts as suppressor of recombination loses at the $\mathrm{BiVO}_{4} /$ solution interface, meanwhile water oxidation is primarily driven by direct $\mathrm{BiVO}_{4}$ holes, Adapted from references ${ }^{[41]}$ - Published by The Royal Society of Chemistry (b) Co-Pi acts "true catalyst", where water oxidation takes place primarily at the Co-Pi sites. Adapted with permission from reference ${ }^{[43]}$. Copyright (2019) American Chemical Society.

(a)

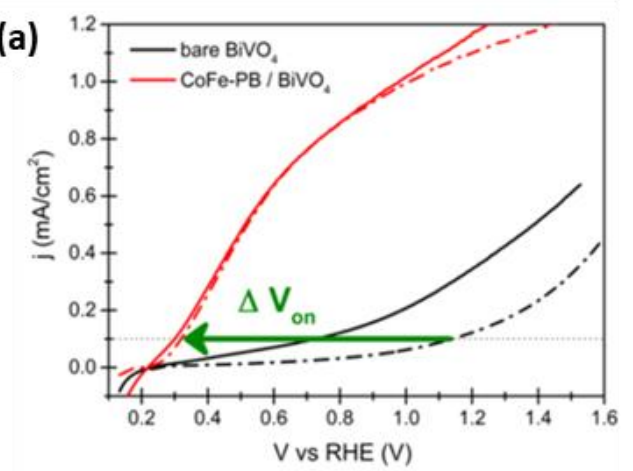

(c)

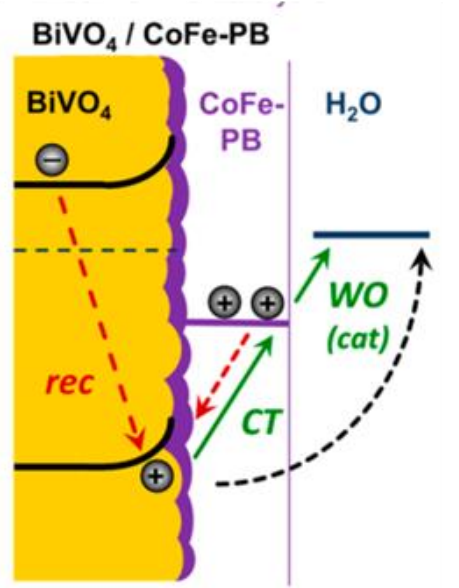

(b)

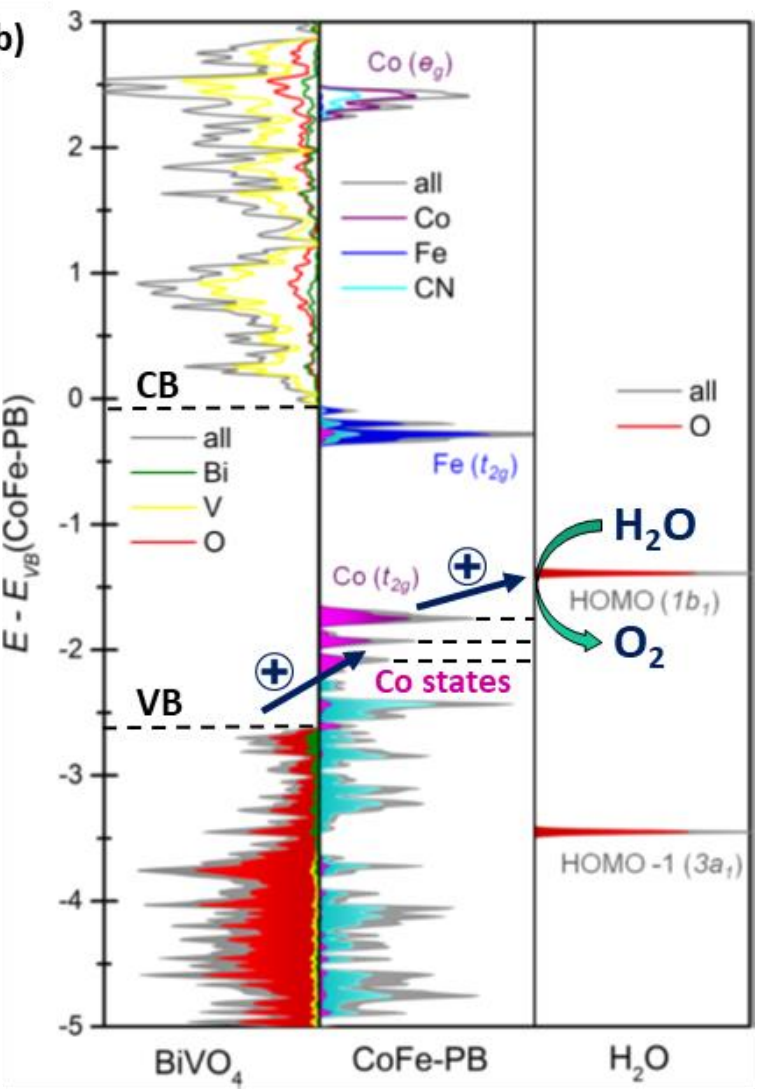




\section{WILEY-VCH}

Figure 3. (a) Linear sweep voltammetry of bare and Co-Fe PB modified $\mathrm{BiVO}_{4}$ photoanode, recorded with $50 \mathrm{mV} \mathrm{s}^{-1}$ (straight lines) and $1 \mathrm{mV} \mathrm{s}^{-1}$ (dashed lines) scan rate, showing the shifted onset of photocurrent. (b) Densities of states of $\mathrm{BiVO}_{4}, \mathrm{CoFe}-$ $\mathrm{PB}$ and $\mathrm{H}_{2} \mathrm{O}$ molecule aligned by their $\mathrm{O} 2 \mathrm{~s}$ bands. (c) Pathways of charge transfer thought water oxidation, elucidated by time-resolved absorption spectroscopies investigation. Adapted from references ${ }^{[52]}$ and ${ }^{[53]}$. 